\title{
Copepa услуг
}

УДК 338.46

КАЗНАЧЕЕВА АЛЕНА АИЕКСАНДРОВНА

к.пед.н., дочент, доцент кафедры кафедра «Туризм и гостиничное дело»,

Институт сервиса, туризма и дизайна (филиал) Северо-Кавказского федерального университета в г. Пятигорске,

e-mail:impir@mail.ru

КАРТАШЕВА ОЛЬГА АЛЕКСАНДРОВНА

к.и.н., дочент кафедры кафедра «Туризм и гостиничное дело»,

Институт сервиса, туризма и дизайна (филиал)

Северо-Кавказского федерального университета в г. Пятигорске,

e-mail:impir@mail.ru

НУРОЯНОВА АНАСТАСИЯ ВАЛЕРЬЕВНА

магистрант 2-го года обучения направление подготовки 43.04 .03 «Гостиничное дело»

Институт сервиса, туризма и дизайна (филиал)

Северо-Кавказского федерального университета в г. Пятигорске,

e-mail: impir@mail.ru

\section{DOI 10.26726/1812-7096-2019-3-81-86 \\ BНЕАРЕНИЕ НОВЫХ ТЕХНОЛОГИЙ ОБСАУЖИВАНИЯ В ГОСТИНИЧНОМ БИЗНЕСЕ}

Аннотауия. Целью работы является определение инновационной деятельности гостиничного бизнеса и определение нововведений, которые гарантируют предприятию огромные преимущества перед конкурентами в данной сфере услуг. В работе применялись теоретические методы, описательный, логическое обобщение, эмпирический метод. В результате внедрения новых идей и знаний для лучшего удовлетворения потребностей клиентов гостиничного предприятия в работе выявлены с позищии финансового потенциала применение разнообразных видов технологии, примеры разработки новых программ

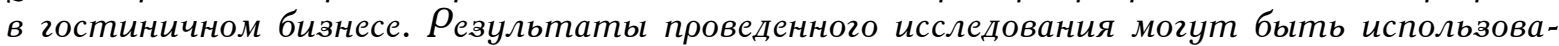
ны в гостиничном бизнесе, сетевыми отелями при развитии автоматизированной системы управления для предприятий индустрии гостеприимства. В условиях высокой конкурентности гостиничные предприятия прилагают максимум усилий для того, чтобы оставаться высокоэффективными и конкурентоспособными. С иелью добиться преимущества над конкурентами необходимо разрабатывать и внедрять новые технологии по обслуживанию своих клиентов. Таким образом, инновации имеют все больщее значение и обеспечивают гостиничному бизнесу превосходства над конкурентами.

Ключевые слова: гостиничный бизнес, гостиничная индустрия, инновауионные технологии, отельер, технологии обслуживания.

KAZNACHEEVA ALENA ALEXANDROVNA

K. PED.n., associate Professor, associate Professor of the Department "Tourism and hotel business», Institute of service, tourism and design (branch) North Caucasus Federal University in $\rho_{\text {yatigorsk, }}$ e-mail: impir@mail.ru

KARTASHEVA OLGA ALEXANDROVNA Ph. D., associate $\rho_{\text {rofessor of the Department "Tourism and hotel business», }}$ Institute of service, tourism and design (branch) North Caucasus Federal University in Pyatigorsk, e-mail:impir@mail.ru 
КАРТАШЕВА О.А., КАЗНАЧЕЕВА А.А., НУРОЯНОВА А.В.

ВНЕДРЕНИЕ НОВЫХ ТЕХНОЛОГИЙ ОБСЛУЖИВАНИЯ В ГОСТИНИЧНОМ БИЗНЕСЕ

NUROYANOVA ANASTASIA VALERIEVNA

master's degree student of the 2nd year of training direction 43.04.03 "Hotel business»

Institute of service, tourism and design (branch)

North Caucasus Federal University in $\rho_{\text {yatigorsk, }}$ e-mail:impir@mail.ru

\section{THE INTRODUCTION OF NEW SERVICE TECHNOLOGIES IN THE HOTEL BUSINESS}

Abstract. The aim of the work is to determine the innovative activity of the hotel business and the definition of innovations that guarantee the company a huge advantage over competitors in this service sector. The paper used theoretical methods, descriptive, logical generalization, empirical method. As a result of the introduction of new ideas and knowledge to better meet the needs of customers of the hotel company in the work identified from the standooint of financial potential the use of various types of technology, examples of the development of new programs in the hotel business. The results of the study can be used in the hotel business, chain hotels in the development of an automated control system for the hospitality industry. In a highly competitive environment, hotel companies are making every effort to remain highly efficient and competitive, in order to gain an advantage over competitors, it is necessary to develop and implement new technologies to serve their customers. Thus, innovation is increasingly important and provides the hotel business with a competitive edge.

Keyword: Hotel business, hotel industry, innovative technologies, hotelier, service technologies.

В современную эпоху научно-технического прогресса, который коснулся практически всех сфер общественной жизни, особое значение имеют инновации и новые технологии именно в гостиничном бизнесе. Ведь их применение сказывается на высококонкурентной борьбе гостиниц и отелей за своих клиентов.

Перед ведущими специалистами в гостиничной индустрии ставятся задачи, среди которых главной является привлечение как можно большего количества постоянных клиентов и получение прибыли от данных услуг. Достичь таких поставленных перед собой задач без внедрения новых технологий практически невозможно, поэтому внедрение и использование новых технологий обслуживания в гостиничном бизнесе является достаточно актуальной проблемой, так как способствует повышению качества обслуживания клиентов и эффективности деятельности гостиниц в целом.

На сегодняшний день инновационная деятельность гостиничного бизнеса основывается на деятельности в 2 сферах [1]:

1. Сфера обеспечения материально-технических условий оказания услуг потребителям.

2. Сфера увеличения ассортимента предоставляемых клиентам услуг.

Большинство современных гостиниц и отелей для того, чтобы повысить привлекательность своих услуг и создать дополнительную выгоду в глазах клиентов, предвосхищая желания гостя, внедряют дополнительные продукты, способные повысить лояльность клиентов той или иной гостиницы. Среди них:

- услуги бизнес-центра и конференц-залов, оборудованных новейшими коммуникационными и информационными ресурсами;

- услуги банкетных залов;

- услуги лечебно-оздоровительных помещений;

- продажа авиабилетов, билетов в кинотеатры, театры, концерты;

- проведение экскурсий.

К примеру, в отелях известных западных брендовых сетей в последние годы внедрено и успешно применяется так называемое «инклюзивное обслуживание каждого гостя», которое предполагает, что в номерах устанавливаются определенные системы запоминания предпочтений клиента (музыку, которую он слушал; комфортный микроклимат и яркость освещения; температуру воды в ванной комнате и воздуха в номере) [2]. Как показывает практика, это нововведение позволяет повышать лояльность клиентов и их удовлетворенность обслуживанием. 
На внедрение и использование вышеперечисленных дополнительных услуг влияют 3 основных фактора:

1. Отношение той или иной гостиницы к определенной категории - определяет формирование материально-технического оснащения и совокупности дополнительных услуг, которые предоставляет гостиница.

2. Осуществление деятельности гостиницы на определенном сегменте рынка - определяет направление инновационного развития по поводу детального учета спроса на услуги постоянных клиентов гостиницы.

3. Гостиничная специализация - направлена на разработку и внедрение таких новых технологий, которые способствуют конкурентоспособности службы гостиницы, определяющей его специализацию.

На сегодняшний день одним из основных нововведений в гостиничном бизнесе является применение интернет-технологий, которые позволяют потенциальному клиенту либо персоналу гостиницы зайти в Сеть и найти всю актуальную информацию о ней. Именно на российском рынке наиболее востребованными подобными продуктами являются Opera Fidelio и Epitome PMS, в которых хорошо реализована система доступа и есть возможность расширять необходимый набор электронных инструментов для управления с помощью сторонних продуктов под каждый конкретный случай.

Высокая конкуренция среди отельеров побуждает их искать все более инновационные и продуманные технологии, которые смогли бы повысить привлекательность своего отеля и качество предоставляемых услуг. Поэтому сейчас инновационные технологии достигли высокого уровня, который объясняется тем, что электронная дистрибьюция совместно с системами бронирования, организованная в единый управляющий комплекс, позволяет в онлайн-режиме руководить бронированием сразу по нескольким каналам продаж. Рассмотрим, например, бизнес-отели, которые предпочитают использовать 2 системы бронирования одновременно: глобальные (GDS), которые являются хорошим инструментом и каналом рекламы отеля, и альтернативные (ADS) [3].

Одним из наиболее важных инновационных технологий является перспективное решение для сетей отелей, работающее на технологии Saas - Libra OnDemand CRMB, которое в 2009 году внедрила компания Либра Хоспиталити и которое сейчас успешно функционирует. Основными характеристиками этой программы являются следующие:

1. Полное управление отделом продаж и маркетингом отеля. Включает в себя максимальную автоматизацию задач работников коммерческого подразделения и способствует планированию деловых встреч, телефонных переговоров и автоматическое календарное расписание менеджеров.

2. Возможность сбора аналитики отдельно по каждому клиенту. Включает отслеживание данных по доходности от каждого клиента (количество броней и проведенных в отеле ночей, полученный доход и средний тариф на каждого клиента и т. д.). Это позволяет иметь в виду предпочтения клиента и подходящие ему договорные условия.

3. Возможность управления лояльностью и разработки методов поощрения постоянных клиентов. Предполагает программу, в которой постоянные клиенты получают сертификаты, бонусы и скидки.

4. Эффективное управление проводимыми в отеле мероприятиями. Включает возможность планирования нагрузки на конференц-залы, составления банкетного меню, продуктивного ведения конференций и семинаров.

На наш взгляд, во внедрении и применении новых технологий обслуживания в гостиничном бизнесе важную роль играет кадровый, финансовый и информационно-технический потенциал.

С позиции кадрового потенциала внедрению новых технологий обслуживания в гостиничном бизнесе могут способствовать [4]:

- практико-ориентировочное образование и отождествление теоретических научный знаний в практическую форму использования их в предпринимательстве посредством проведения части дисциплин в гостиницах;

- новые методы обучения работников гостиниц и их более быстрая интеграция в коллек- 
тив, которая позволяет повысить производительность труда.

С позиции финансового потенциала необходимо применить следующие технологии:

1. Выявление новых стратегических ресурсов и новых методов управления человеческими ресурсами, которое включает в себя понимание управленцами путей развития капитала, условий оплаты и снижения потерь из-за ошибок работников гостиницы.

2. Высокопродуманная тарифная политика и использование системы премирования работников для их стимулирования на продажу новых и более дорогих услуг отеля.

3. Высокоэффективное управление ликвидностью, активами гостиницы и ее издержками.

С позиции информационно-технического потенциала новыми технологиями по обслуживанию в гостиничном бизнесе могут выступать следующие:

1. Разработка новых программ в гостиничном бизнесе, таких как OPERA, Libra Hospitality, Эдельвейс, Отель, Cеnium, системы ERP, системы CRM.

2. Использование глобальных и альтернативных систем бронирования номеров в гостинице.

3. Использование системы онлайн-видеонаблюдения.

4. Использование системы магнитных замков.

Однако нужно помнить, что внедрение новых технологий обслуживания в гостинице должно преследовать определенные цели, что в настоящее время происходит далеко не всегда, не говоря уже о стратегии развития гостиничного предприятия, которая далеко не всегда зависит от текущей ситуации на рынке и имеющихся перспективных тенденций.

На территории Ставропольского края расположены существенные рекреационные ресурсы, достаточно отметить, что на долю Кавказских Минеральных Вод приходится более 70 \% общего потока туристов региона. Ставропольский край в 2018 году занял 7-е место в Национальном туристическом рейтинге. Общая динамика туристической сферы свидетельствует о наращивании объемов: так, в 2018 году произошло увеличение количества туристических объектов на 31 единицу, общая конечная емкость размещения которых составила 878 мест. В рамках повышения квалификации и обучения работников туристической сферы в 2017 году прошли обучение дистанционным способом 278 человек.

В регионе достаточно активно развивается деловой туризм, этнографический и историкокультурный туризм, хотя лечебный туризм традиционно остается приоритетным направлением.

В 2018 году численность отдыхающих в Ставропольском крае возросла на 2,9 \%, или на 39,3 тыс. человек. На рисунке отражена структура отдыхавших в Ставропольском крае в 2018 году.

Общая стоимость оказанного объема туристических услуг составила в 2018 году по Ставропольскому краю 24,5 млрд руб. Доля туризма в структуре ВВП Ставропольского края составляет около 19,4 \%, что является существенным уровнем, а для большинства регионов Российской Федерации - недостижимым.

Состояние и перспективы развития туристско-рекреационного потенциала Ставропольского края изложены в Стратегии развития рекреационно-туристского комплекса Ставропольского края до 2030 года. Она состоит из шести разделов и приложений, каждый из которых дает оценку состояния на сегодняшний день, а также перспектив развития в будущем основных направлений развития туризма в регионе с выделением приоритетных территорий, выявление их привлекательности и этапности развития.

Таким образом, в современную эпоху научно-технического прогресса, чтобы любой гостинице оставаться конкурентоспособной и высокоэффективной, руководителям и отельерам необходимо разрабатывать и внедрять новые технологии по обслуживанию своих клиентов, учитывая при этом кадровый, финансовый и информационно-технический потенциал. Ведь именно инновации могут способствовать не только высокой производительности труда, но и высокому уровню прибыли.

\section{Литература}

1. Амирова З. Б. Инфраструктура туризма и гостеприимства: учебное пособие / З.Б. Амирова. - М.: Альтаир-МГАВТ, 2014 2. $-85 \mathrm{c}$.

2. Боголюбова С. А. Эколого-экономическая оченка рекреационных ресурсов: учебное пособие / C. A. Боголюбова. - М.: Академия, 2009. - 256 с.

3. Валеева Е. О. Современные технологии организации туристской деятельности: учебное пособие / E.

О. Валеева - СПб.: Троиикий мост, 2015. - 194 с.

4. Васина С. М. Технологии туристско-рекреаџионного проектирования и освоения территорий: учебно 
-методическое пособие / С. М. Васина. - Йошкар-Ола: ПГТУ, 2014. - 72 с.

5. Воронцова Е. А. Индустрия туризма в условиях экономического кризиса: тенденции и перспективы paзвития // Studia Humanitatis Borealis. - 2015. - № 1. - C. 59-67.

6. Инновации в гостиничном бизнесе. Смысл применения и выгоды // Официальный сайт агентства инноваций и развития экономических и сочиальных проектов [Электронный ресурс]. Режим доступа: https://www.innoros.ru/publications/interesting/13/innovatsii-v-gostinichnom-biznese-smysl-primeneniya-ivygody (дата обрашения 18.11.2018), своб. - Загл. с экрана.

7. Инновации и технологии в гостиничном бизнесе // Информационный проект "Shopolog». [Электронный ресурс]. Режим достуnа: https://www.shopolog.ru/metodichka/idei-dlya-malogo-biznesa/ innovacii-i-texnologii-v-gostinichnom-biznesel (дата обращения: 17.11.2018), своб. - Загл. с экрана.

8. Кожаев Ю. П. Маркетинг в туристской индустрии: учебное пособие / Ю. П. Кожаев. - М.: ЮНИТИ -ДАНА, 2016. - 303 с.

9. Котанс А. Я. Технология соичильно-культурного сервиса и туризма: учебное пособие / А.Я. Котанс. М.: Флинта, 2014.-384c.

10. Ланг В. В., Исаева А. Г. Развитие сферы туризма в Ставропольском крае // Региональные детерминанты и закономерности развития экономики: материалы Международной научно-практической конференции / главный редактор о. Б. Бигдай. - 2018. - С. 151-153.

11. Макринова Е. И., Авилова Н. А., Ушаков Р. Н. Роль и место инновационных технологий в развитии ресурсного потеничала гостиничного предприятия // Фундаментальные исследования. - 2016. - № 43. - C. 624-628.

12. Менеджмент туризма: учебник [Текст] / А. Д. Чудновский, Н. В. Королев, Е. А. Гаврилова, М. А. Жукова, Н. А. Зайчева. - М.: Федеральное агентство по туризму, 2014. - 576 с.

13. Меняйлов А. А. Историко-культурный потенииал региона как основа формирования туристского образа дестинации // Научное наследие Ф. А. Щербины: казачество и история Кавказа; сборник материалов ХVIII Международной научно-практической конференщии. - Краснодар, 2018. -С. $220-223$.

14. Меняйлов А. А. Предпосылки формирования и развития туристического потенциала СевероКавказского федерального округа // Вестник Северо-Осетинского государственного университета имени Коста Левановича Хетагурова. - 2018. - № 4. - С. 98-101.

15. Меняйлов А. А. Роль нащионального менталитета в формировании гостиничного продукта // Вестник Академии знаний. - 2018 - № 5 (28). - C. 272-276.

16. Морозов М. А., Аристов П. О. Влияние туризма на экономику региона: на примере Ставропольского края // Вестник Российского нового университета. Серия: Человек и общество. - 2018. - № 2. - С. 6975 .

17. Подколзина И. М., Чечелева А. А., Кузнечова Н. А. Анализ основных тендениий развития лечебного туризма на территории Ставропольского края // Лучшая научная статья 2018: сборник статей ХV Международного научно-практического конкурса. - 2018. - С. 98-106.

18. Стратегия развития туризма в Ставропольском крае до 2030 года // [Электронный ресурс]. Режим доступа: http://mincultsk.ru/turist/2015-05- 20-18-53-06, своб. - Загл. с экрана.

19. Федеральная служба государственной статистики [Электронный ресурс]. Режим доступа: http:// cbsd.gks.ru, своб. - Загл. с экрана.

20. Федеральное агентство по туризму Министерство культуры Российской Федераџии [Электронный ресурс]. Режим доступа: http://www.russiatourism.ru, своб. - Загл. с экрана.

21. Халдина А. Д. Бизнес-идеи по внедрению инновационных технологий в деятельность гостиничных предприятий // Материаль VII Международной студенческой научной конферениии «Студенческий научный форум - 2015» [Электронный ресурс]. Режим доступа: https://scienceforum.ru/2015/ article/2015014237 (дата обращения: 17.11.2018), своб. - Загл. с экрана.

\section{References:}

1. Amirova Z. B. tourism and hospitality Infrastructure: textbook/Z. B. Amirova. M. : Altair-MGAVT, 2014, $85 \mathrm{p}$.

2. Bogolyubova S. A. Ecological and economic assessment of recreational resources: textbook/S. A. Bogolyubova. Moscow: Academy, 2009. 256 p.

3. Modern technologies of the organization of tourist activity: textbook / E. O. Valeeva-SPb.: Trinity bridge, 2015. $194 \mathrm{p}$.

4. Vasina S. M. Technologies of tourist and recreational design and development of territories: educational and methodical manual /S. M. Vasina. Yoshkar-Ola: PGTU, 2014. 72 p.

5. Vorontsova E. A. tourism industry in conditions of economic crisis: trends and prospects of development // Studia Humanitatis Borealis. 2015. No. 1. P. 59-67.

6. Kozhayev J. P. Marketing in tourism industry: a training manual / Y. P. Kozhayev. M.: YUNITI-DANA, 2016. $303 \mathrm{p}$.

7. Kotans A. Ya. Technology of social and cultural service and tourism: textbook / A. Ya. Kotans. M.: Flint, 2014. $384 p$.

8. Lang V. V., Isaeva A. G. Development of tourism in Stavropol Krai // Regional determinants and patterns of economic development: materials of the International scientific-practical conference / editor-in-chief $O$. B. Bigday. 2018. P. 151-153.

9. Marinova E. I., Avilova N. A. Ushakov R. N. The role and place of innovative technologies in the development of the resource potential of the hotel enterprise // Fundamental research. 2016. No. 4-3. P. 624-628.

10. Tourism management: textbook [Text] / A. D. Chudnovsky, N. In. Korolev, E. A. Gavrilova, M. A. Zhukova, N.. Zaitsev. Moscow: Federal Agency for tourism, 2014. $576 \mathrm{p}$. 
КАРТАНЕВА О.А., КАЗНАЧЕЕВА А.А., НУРОЯНОВА А.В.

ВНЕДРЕНИЕ НОВЫХ ТЕХНОЛОГИЙ ОБСЛУЖИВАНИЯ В ГОСТИНИЧНОМ БИЗНЕСЕ

11. Menyailov A. A. Historical and cultural potential of the region as a basis for the formation of the tourist image of the destination // scientific heritage Of F. A. Shcherbina: Cossacks and the history of the Caucasus; proceedings of the XVIII International scientific and practical conference. Krasnodar, 2018. P. 220-223.

12. Menyailov A. A. Prerequisites for the formation and development of the tourism potential of the North Caucasus Federal district // Bulletin of the North Ossetian state University named after Costa Levanovich Khetagurov. 2018. No. 4. P. 98-101.

13. Menyailov A. A. the Role of the national mentality in the formation of the hotel product // Bulletin of the Academy of knowledge. 2018 No. 5 (28). P. 272-276.

14. Morozov M. A., Aristov P. O. The impact of tourism on the economy of the region: on the example of Stavropol territory // Bulletin of the Russian new University. Series: Man and society. 2018. No. 2. P. 69-75.

15. Podkolzina I. M., Cecelia A. A., Kuznetsova N. A. analysis of the main trends in the development of medical tourism in the Stavropol territory // The best scientific article 2018: collection of papers of Xv International scientific and practical competition. 2018. P. 98-106.

16. Haldina A. D. Business ideas for the introduction of innovative technologies in the activities of hotel enterprises. // Materials of the VII international student scientific conference "Student scientific forum - 2015. [An electronic resource]. Access mode: https://scienceforum.ru/2015/article/2015014237 (date accessed: 17.11.2018), free. Heading from the screen.

17. Innovations and technologies in the hotel business// Information project «Shopolog». [An electronic resource]. Access mode: https://www.shopolog.ru/metodichka/idei-dlya-malogo-biznesa/innovacii-i-texnologii-vgostinichnom-biznesel (accessed: 17.11.2018), free. Heading from the screen.

18. Innovations in the hotel business. Sense of application and benefits // Official website of the Agency for innovation and development of economic and social projects. [An electronic resource]. Access mode: https:// www.innoros.ru/publications/interesting/13/innovatsii-v-gostinichnom-biznese-smysl-primeneniya-i-vygody (accessed 18.11.2018), free. Heading from the screen.

19. Strategy of tourism development in the Stavropol region until 2030. [An electronic resource]. Access mode: http://mincultsk.ru/turist/2015-05 - 20-18-53-06, free. Heading from the screen.

20. Federal state statistics service. [An electronic resource]. Access mode: http://cbsd.gks.ru, free. Heading from the screen.

21. Federal Agency for tourism Ministry of culture of the Russian Federation [An electronic resource]. Access mode: http://www.russiatourism.ru, free. Heading from the screen. 